\title{
DO MODUS PARISIENSIS AO RATIO STUDIORUM: OS JESUÍTAS E A EDUCAÇÃO HUMANISTA NO INÍCIO DA IDADE MODERNA
}

DOI: http://dx.doi.org/10.1590/2236-3459/57630

\author{
João Batista Storck \\ Universidade do Vale do Rio dos Sinos, Brasil.
}

\section{$\cos 80$}

\begin{abstract}
Resumo
O processo constitutivo do Ratio studiorum, enquanto método pedagógico, bem como a relação deste com o surgimento e a estruturação do Humanismo no início da Idade Moderna, é o tema do presente artigo. No desenvolvimento do trabalho, utilizamos uma vasta bibliografia existente sobre o tema, assim como, realizamos a consulta em documentos específicos da Companhia de Jesus. A relevância do presente trabalho justifica-se considerando o fato de que o método pedagógico desenvolvido pelos jesuítas teve uma grande influência sobre a educação e a cultura de modo geral, contribuindo para a estruturação do humanismo moderno e contemporâneo.

Palavras-chave: modus parisienses, ratio studiorum, jesuítas, humanismo.
\end{abstract}

\section{FROM PARISIENSIS MODUS FOR THE RATIO STUDIORUM: THE JESUITS AND THE HUMANISTIC EDUCATION AT THE BEGINNING OF MODERN AGE}

\section{Abstract}

It is in this article show the process of formation of the Ratio studiorum, while teaching method, as we know nowadays as well as the relationship with the emergence and structure of Humanism in Early Modern Age. In developing this work, we use an extensive bibliography, as well as perform a research on specific documents of the Society of Jesus. The relevance of this work is justified considering the fact that the teaching method developed by the Jesuits had a great influence on education and culture in general has contributed to the structuring of modern humanism and contemporary.

Key-words: modus parisiensis, ratio studiorum, jesuits, humanism.

\section{DESDE EL MODUS PARISIENSIS A LA RATIO STUDIORUM: LOS JESUITAS Y LA EDUCACIÓN HUMANÍSTICA EN EL INICIO DE LA EDAD MODERNA}

Resumen

Este artículo tiene como objetivo presentar el proceso constitutivo de la Ratio studiorum, como método pedagógico, tal como la conocemos hoy en día y su relación con la aparición y la 
estructuración del humanismo en la Edad Moderna. En el desarrollo de este trabajo, utilizamos una extensa bibliografía existente y realizamos la consulta sobre los documentos específicos de la Compañía de Jesús. La relevancia de este trabajo se justifica teniendo en cuenta el hecho de que el método de enseñanza desarrollado por los jesuitas tuvo una gran influencia en la educación y la cultura, contribuyendo en la estructuración del humanismo moderno y contemporáneo

Palabras-clave: ratio studiorum, modus parisiensis, jesuitas, humanismo.

\section{DE LA MODUS PARISIENSIS AU RATIO STUDIORUM: LES JÉSUITES ET L'ÉDUCATION HUMANISTE AU DÉBUT DE L'ÂGE MODERNE}

\section{Résumé}

II s'agit dans cet article présenter le processus qui a crée le Ratio studiorum pendant que un méthode pédagogique comme nous le conaissons aujourd'hui, ainsi que la relation avec l'émergence et l'organization de l'humanisme au début de l'ère moderne. Dans elaboration de ce travail, nous utilison une large littérature existante, ainsi que, d'effectuer la requête sur des documents specifiques de la Compagnie de Jésus. La pertinence de ce travail est justifié compte tenu du fait que la méthode de enseignement dévéloppée par les Jésuites a eu une grande influence sur l'éducation et la culture en général en ayant contribué a la structuration de l'humanisme moderne e contenporain.

Mots-clé: ratio studiorum, modus parisiensis, jésuites, humanisme. 


\section{A educação nas origens da Companhia de Jesus}

\section{criação oficial da Companhia de Jesus ocorreu com a publicação da Carta \\ A Apostólica Regimini militantis Ecclesiae, que aprovou a existência da nova Ordem religiosa em 27 de setembro de 1540, emitida pelo papa Paulo III, e foi confirmada em 21 de julho de 1550, pelo papa Julio III na Carta Apostólica Exposcit debitum. Canonicamente aprovada, a ordem passou a organizar a} sua ação apostólica. A aprovação papal aconteceu a partir da chamada Fórmula do Instituto, na qual aparece o fim para o qual foi instituída a Companhia e os meios para realizá-lo:

Esta foi instituída principalmente para o aperfeiçoamento das almas na vida e na doutrina cristã, e para a propagação da fé, por meio de pregações públicas, do ministério da palavra, dos Exercícios Espirituais e obras de caridade, e nomeadamente pela formação cristã das crianças e dos rudes. (Giuliani, 1991, p. 292)

Analisando-se a Fórmula do Instituto ${ }^{1}$, nada permite afirmar que a Companhia de Jesus, nos cinquenta anos seguintes a sua fundação, desenvolveria um método de ensino chamado Ratio studiorum, assimilando muitos elementos do humanismo renascentista, que já há mais tempo se apropriava das letras gregas e latinas.

A primeira experiência na área educacional ocorreu com a aceitação de um colégio em Gandia, fundado pelo duque Francisco de Borja, em 1545, e que se tornou universidade em 1547. Não obtendo, no entanto, êxito pela escassez de alunos, a mesma foi suprimida em 1556.

Enquanto o colégio de Gandia se estruturava veio uma solicitação do vice-rei da Sicília, junto e com as autoridades desta cidade, que se comprometeram com os subsídios econômicos para a fundação de um colégio na cidade de Messina. O colégio foi oficialmente inaugurado em 1548, sendo o primeiro da Ordem destinado para estudantes leigos, dirigido por jesuítas.

Devido à fundação destes colégios e às solicitações que chegavam para a abertura de outros, houve a necessidade de buscar um ordenamento único e planejado do ensino que valesse para todos os colégios e universidades da Ordem. As normas internas dos colégios existentes, estruturadas a partir do Modus parisiensis, serviram de ponto de partida para a elaboração das primeiras versões do ordenamento de estudos. Coube ao padre Nadal a responsabilidade de introduzir nos colégios e universidades da Companhia, o Modus parisiensis como método pedagógico e, de elaborar os primeiros programas de ensino, que culminaram na redação definitiva da Ratio studiorum de 1599 (Gomes, 1995).

\section{Os exercícios espirituais e o humanismo cristão renascentista como fonte e dinamismo do agir educacional da Companhia de Jesus}

Para que se entenda, com mais propriedade, os princípios que regeram a elaboração do Ratio studiorum é necessário compreender as fontes originárias de onde brotaram estes elementos. Kolvenbach (1993), ao abordar a respeito das fontes da pedagogia inaciana, diz que desde as suas origens, no século 16, a educação jesuíta

\footnotetext{
${ }^{1}$ As Fórmulas do instituto, também chamadas Documentos da fundação, são, junto com as Constituições, os documentos mais importantes da Companhia de Jesus, na medida em que expressam não somente o carisma da Ordem, mas como o mesmo devia se realizar concretamente. 
orientou-se para o desenvolvimento e a transmissão de um humanismo cristão, sendo que este tem duas raízes: a experiência espiritual de Inácio de Loyola e os desafios culturais, sociais e religiosos da Renascença e da Reforma na Europa:

Esta espiritualidade habilitou os jesuítas a se apropriarem do humanismo da Renascença e a fundarem uma rede de centros educativos, que significavam uma renovação e respondiam às necessidades urgentes do seu tempo. A fé e o fomento da humanitas trabalhavam de mãos dadas (Kolvenbach, 1993, p. 89)

Essa primeira fonte, conhecida como Exercícios espirituais, foi vivenciada e sistematizada por Inácio de Loyola num livro com esse nome. Não se trata de um tratado de Teologia nem de espiritualidade, mas um manual prático com indicações precisas para o orientador e o exercitante e sugestão de temas para a oração a partir dos textos da Bíblia. Toda a estrutura dos Exercícios pode ser resumida em alguns princípios fundamentais expressos num tópico denominado Princípio e fundamento dos exercícios espirituais, onde consta que "o Homem é criado para louvar, reverenciar e servir a Deus Nosso Senhor, e mediante isso salvar a sua alma. E as outras coisas sobre a face da terra são criadas para o homem e para o ajudarem a atingir o fim para o qual é criado" [EE. 1], ou seja, Deus é a referência última do homem. Tudo o que Deus criou é bom, e todas as coisas criadas conduzem o homem para Deus e para a sua glória. Nesta ótica, o fim da educação é levar o ser humano, principal criatura de Deus, à perfeição, conduzindo-o para o fim ao qual foi criado: a maior glória de Deus. Neste sentido, se um dos frutos dos Exercícios é o decidir-se pela vontade divina, mediante a educação da vontade humana, ficaria ao ensino das letras e humanidades o encargo de cultivar a inteligência, pois a perfeição humana não seria apenas perfeição moral e espiritual, mas também perfeição intelectual.

A segunda fonte que deu origem à educação jesuíta, citada por Kolvenbach (1993), é o humanismo cristão. Como vimos, a expressão letras humanas era a forma mais comum que se utilizava para os estudos literários clássicos e as áreas relacionadas. $\mathrm{Na}$ língua vernácula fazia-se referência às humanidades. Os jesuítas não seguiram um humanismo doutrinário que se opunha à Teologia, nem promoveram uma perspectiva secularizante do mundo. Eles tomaram o termo humanismo em sua conexão com as letras humanas, o estudo e o gosto pelas línguas e a literatura clássica grega e latina. Compreendiam que nada do que é humano se deve considerar alheio aos estudos. Ou seja, a literatura, as artes e a filosofia que abordam e refletem sobre a natureza e sobre a pessoa humana são boas em si. No pensar dos jesuítas se podia combinar o cultivo da piedade com a erudição, uma não excluindo a outra.

Une-se a concepção espiritual dos Exercícios com as letras humanas, ou o humanismo cristão, que deu origem ao que podemos denominar humanismo jesuítico que se apresentou de forma mais explícita no Ratio studiorum, muito embora os jesuítas não tenham sido os primeiros nem os únicos a se preocupar em unir a cultura com as aspirações religiosas. No entanto, construíram sua própria síntese teológica, ou seja, o humanismo jesuítico que, como salienta Miranda (2001, p. 84), "surge da concepção de que a as letras humanas, ou o humanismo clássico e os valores evangélicos expressados nos Exercícios espirituais concorriam para a criação do ideal do homem completo da Paidéia humanística cristã". 


\section{O Modus parisiensis como inspiração primeira}

Mas em que consiste o Modus parisiensis que influenciou na elaboração do Ratio studiorum? Por que ele foi adotado pelos jesuitas? Estas interrogações são respondidas quando consideramos dois fatos importantes: a organização interna própria dos colégios parisienses e a maneira de ensinar, igualmente própria dos mestres de Paris, que se estruturou ao longo do tempo e na qual se mesclaram diferentes experiências, não se constituindo, portanto, num método de todo original.

Ocorre que já existia, desde os fins do século 14 nos Países Baixos e na Alemanha, certa variedade de escolas ao redor das Fraternidades dos Irmãos de Vida Comum, fundadas por Gerard Groot (1340-1384). Os elementos característicos nas escolas destes irmãos eram a divisão dos estudantes por classes, cada uma com um mestre e um programa preciso, ordenado e progressivo. Empregavam, também, o Quadrivium aritmética, música, geometria e astronomia -, sendo que cada matéria tinha um professor especializado e as mesmas eram coordenadas com outras disciplinas ensinadas na mesma escola. Além disso, utilizavam a Bíblia para a formação dos jovens no ideal de vida cristã para o qual todas as ciências e letras deveriam estar direcionadas. Outros elementos típicos de sua pedagogia eram a adoção do sistema de decúrias ${ }^{2}$, o exame de passagem para o nível de estudos literários, o cultivo da língua vernácula, os emolumentos para os melhores estudantes, o teatro escolar, as punições e as disputas (O'Malley, 2004; O’Neill; Domíngues, 2001).

As Escolas dos Irmãos de Vida Comum, ao se espalharem por toda a Europa, influenciaram gerações e serviram de modelo para as que surgiriam posteriormente, inclusive para as escolas e a Universidade de Paris. O Modus parisiensis, portanto, foi resultado de uma longa evolução e recebeu várias reformas e adaptações nos séculos seguintes.

\section{A organização interna dos Colégios e da Universidade de Paris}

A organização escolar da Europa, na Idade Média, possuía em seu conjunto uma estrutura muito semelhante. No entanto, a organização de professores e estudantes não era a mesma em todas as partes. Havia, basicamente, dois tipos de organização escolar: a de Paris, em que o modelo de colégios e universidades estava sob o controle dos professores, e a de Bolonha, em que o modelo de colégios e universidade estava sob a influência dos estudantes. Após a reforma feita pelo cardeal de Estouteville, em 1452, enviado pelo papa Nicolau $V$ com a missão de reformar diversas instituições eclesiásticas, principalmente a Universidade de Paris, era esta que controlava os colégios e todo o âmbito estudantil.

No começo do século 16 a universidade se impôs como autoridade plena, sendo que o reitor passou a comandar tudo o que se referia ao regime escolástico e disciplinar dos colégios e seus estudantes. É devido a esta estrutura organizativa e a esta forte autoridade exercida pela universidade sobre os colégios que se deve atribuir, em boa parte, a unidade e a eficácia do sistema educativo de Paris (Ciordia, 2007; Verger, 1997).

\footnotetext{
${ }^{2}$ Tratava-se do sistema em que um aluno treinado ou mais adiantado, decurião, deveria ensinar um grupo de dez alunos, decúria, sob a orientação e supervisão de um inspetor. 
Típico do Modus parisiensis é a definição de funções das distintas autoridades. Regras e mais regras detalhavam as atribuições de cada um dos responsáveis e o modo de cumpri-las. Os jesuítas serão fiéis tributários desta tradição parisiense de origem medieval. Uma grande parte dos primeiros documentos pedagógicos da Companhia de Jesus será constituída por regras de distintos ofícios (Codina Mir, 1968).

A organização das classes, segundo Miranda (2001) e Ciordia (2007), era uma das características mais importantes dos colégios de Paris. Eles adotavam uma organização graduada de classes homogêneas: lectiones, classis, ordines, regulae, loci, etc. Em cada classe era fixado um nível a ser atingido. Nenhum aluno mudava de uma classe inferior para uma superior, sem que fosse assegurado que o mesmo tivesse o grau de conhecimento esperado, medido por exames rigorosos.

Em geral as aulas na Renascença aconteciam da seguinte maneira: antes da lectio ou praelectio, o professor escolhia o trecho de um escritor clássico, latino ou grego, e discorria sobre o mesmo e sobre o proveito a ser tirado da leitura. Assinalava o gênero literário e, depois, fazia a leitura, frase por frase, explicando todos os seus componentes, assinalando os neologismos, os arcadismos, a etimologia das palavras, etc. Além disso, relacionava o autor que estava sendo estudado com outros autores e extraía, finalmente, as ideias filosóficas e os ensinamentos morais. Importante destacar as chamadas glosas, que eram anotações que os alunos se apressavam em copiar e transportar, em seguida, para as margens dos seus textos manuscritos. Como um verdadeiro tesouro, os alunos guardavam essas glosas que comunicavam a ciência do autor explicado pelos professores. A assimilação dos autores clássicos era importante pelo fato de os mesmos serem propostos por mestres do pensamento e modelos de vida virtuosa, algo importante nos estudos humanísticos (Garcia-Villoslada, 1991).

Logo após a lectio se faziam perguntas - quaestiones - do professor ou dos alunos com o objetivo de aprofundar a compreensão do que fora estudado. Utilizavam, também, as disputationes em Latim, com o objetivo de fixar a aprendizagem. Estas se constituíam em competições entre alunos ou de uma parte da classe com a outra, se estendendo, não raro, depois das aulas que tinham duração variada de cinco a sete horas. Mesmo depois do almoço ou da janta aproveitava-se o tempo para fazer exercícios chamados reparationes, que consistiam em repetir a matéria vista em aula. Praticava-se também o reddere lectiones, em que dois alunos tomavam a lição um do outro, em geral antes de as aulas iniciarem. Por seu lado, o professor utilizava a redditio lectionum que consistia em tomar as lições todos os dias, fazendo com que os alunos fizessem um exercício de memória (Miranda, 1996; Weijers, 1997abc).

Diariamente havia um trecho em Latim ou em Grego a ser decorado. Além desses exercícios cotidianos havia os exercícios quinzenais, que eram feitos em sessão pública e consistia em discursos, composições em prosa e verso e disputas dos alunos. Pelas lectiones os alunos enriqueciam o vocabulário. Para isso, cada um possuía um caderno em que transcrevia os assuntos, palavras, ideias ou frases dos autores lidos.

Praticava-se, também, o chamado thema duas ou três vezes por semana, que consistia em uma composição sobre uma frase ou mesmo sobre uma ideia extraída de um autor clássico com o objetivo de fazer com que os alunos desenvolvessem um bom estilo na escrita. Além disso, nas aulas de Retórica, se realizavam exercícios de declamação de autores renomados e ocorriam as disputas - disputatio -, em que cada 
aluno defendia o seu ponto de vista sobre determinado tema ou autor. Estas disputas ocorriam em dias marcados, em geral no sábado ou a cada quinze dias. Estabelecia-se, previamente, a ordem e os ritos a observar, as matérias sobre as quais as disputas deveriam ocorrer, bem como as penas a serem cumpridas por aqueles que eram derrotados.

Entorno das disputas havia todo um jargão especializado que se estenderá aos estudos literários: opponere et respondere, quaestiones facere, conferentiae, collationes, conclusiones, positiones, etc. Além dos estudos ocorriam, igualmente, representações teatrais de peças clássicas, ou peças compostas por professores e alunos que, em geral, eram apresentadas nas festas dos santos patronos das respectivas cidades ou dioceses. Essas representações teatrais foram intensamente cultivadas pelos jesuítas e, geralmente, constavam de diálogos espirituais que ocorriam nas festas da Igreja, como Corpus Christi, Sexta Feira Santa, Natal, Páscoa (Ciordia, 2007; O’Malley, 2004).

Da mesma maneira que o método de Paris era utilizado na pedagogia dos colégios renascentistas, a questão disciplinar teve aí suas origens se estendendo para outros estabelecimentos, com algumas modificações. Por isso, ao se referir ao Modus parisiensis também é importante citar os aspectos relacionados ao controle da disciplina, castigos e prêmios. Uma das práticas de origem medieval existentes nos colégios renascentistas era a existência dos alunos exploratores ou observatores. Estes eram encarregados de denunciar as faltas dos colegas ao diretor. Essa função odiosa fazia com que os que a exercesem fossem chamados de lupi, lobo, pelos colegas. Semelhante era a função exercida pelo decurio. Eram alunos escolhidos entre os mais brilhantes e tinham como função presidir as decúrias, grupos de dez colegas da mesma classe para trabalharem e estudarem em conjunto. Cada decúria tinha por chefe um decurio, sendo que uns observavam os outros e cada decúria cuidava do comportamento da outra para vigiá-los e denunciar suas falhas. O decurio elaborava as chamadas tabellae delatoriae, uma lista com os nomes dos infratores, que tinha o castigo como consequência certa (Ciordia, 2007; Codina Mir, 1968; O’Malley, 2004).

Outra forma de penalidade era o chamado castigo da sala. Esta consistia em açoitar os alunos que haviam transgredido de forma grave alguma norma do colégio e se aplicava no refeitório, na presença dos professores e demais alunos. Uma expressão que os alunos conheciam muito bem era verbis et verberibus: com palavras e com varas. Caso a expressão verbal não surtisse efeito, apelava-se para a vara. Os prêmios eram conferidos aos alunos por ocasião de eventos marcantes, nas disputas ou na conclusão do ano acadêmico (Codina Mir, 1968; Iparraguirre, 1963).

\section{As humanidades nos colégios e na Universidade de Paris}

De acordo com os historiadores, especialmente aqueles dedicados ao estudo do período Medieval, como Etienne Gilson, Martin Grabman, Marie-Domique Chenu, a tradição do humanismo começou no século 12, na época do florescimento das escolas urbanas, e fixou-se no século 15, nas academias eruditas da Renascença italiana. Nesse itinerário secular a tradição do humanismo atingiu sua expressão teórica mais elevada nas obras dos teólogos do século 13, sobretudo, na obra de Tomás de Aquino. Nos séculos 15 e 16 o espírito do humanismo atingiu sua maturidade, tendo como expoentes Marsílio Ficino, Pico della Mirandola, Erasmo de Rotterdam e Tomás Moro (Vaz, 2001). 
De uma forma, ou de outra, a maioria dos pensadores europeus dos séculos 15 e 16 era, majoritariamente, ligada ao humanismo e continuadores do movimento iniciado por Francesco Petrarca (1304-1374). Sua poesia e prosa tornaram-se referência por tratar os sentimentos humanos com elegância e estilo. Mesmo que alguns dos primeiros humanista italianos, a começar pelo próprio Petrarca, não se encontrem diretamente ligados à docência, a segunda geração de humanistas e os principais expoentes do humanismo europeu, estão na maioria relacionados à história da Pedagogia. Segundo Soares (1995, p. 811) os autores dos tratados pedagógicos desta época são "subsidiários tanto do ponto de vista estético, quanto doutrinal, dos ideais educativos do humanismo grego latino, que confluem com a ética cristã, numa interdependência e complementaridade entre humanitas e pietas, a exemplo do que acontecera com os autores da Patrística".

Enquanto movimento intelectual e literário, o humanismo pode ser definido como a doutrina ou o conjunto de tendências de caráter filosófico e, mais particularmente, filológico que, durante o Renascimento italiano dos séculos 14 e 15, se orientaram no sentido de reviver e imitar os modelos artísticos, literários e científicos da Antiguidade grego-latina (Fernand, 1946). Este toma como seu, aquele ideal de um tempo educacional e político, que figuras como Cícero (106-43 a.C.) haviam propugnado em Roma na época da República: o ideal da humanitas, palavra com a qual se traduz para o Latim o termo grego Paidéia, ou seja, educação. Com o conceito de humanitas se quis denotar uma operação cultural: a construção do homem civil que vive e opera na sociedade humana (Aquino, 2000; Chervel; Compère, 1997; Puledda, 2001).

Embora o humanismo se constitua, em parte, numa reação renascentista contra certo tipo de cristianismo, bem como contra o pensamento e a filosofia medieval, cujos ideais se estruturavam sobre princípios religiosos, este, no entanto, não deve ser visto, segundo Monteiro (2002), como um movimento anticristão ou antimedieval, mas como uma etapa do processo histórico europeu:

A exaltação religiosa das consciências não supõe a recusa da religião, como aconteceu com numerosos Humanistas que respeitaram os valores religiosos. O verdadeiro Humanismo, como o concebiam os pedagogos e educadores, era o que entroncava a visão cristã da vida no tronco da antiga 'virtus', o que implicava precisamente a busca de uma educação pessoal com interesses profundamente morais e religiosos. (Monteiro, 2002, p. 8)

É importante ressaltar que o humanismo não foi um fenômeno exclusivo da Itália, mas ocorreu também na Alemanha, na França, na Inglaterra e na Espanha. No entanto, todos são devedores do humanismo italiano desde suas origens no Quattrocento, que se expandiu por toda a Europa, sendo também marcado pela Reforma Protestante de Lutero (1483-1546) e Calvino (1509-1564), bem como, depois, pela Contrarreforma Católica.

As novas correntes humanistas surgidas na Itália se expandiram pela Europa graças ao impulso da imprensa e entram na Universidade de Paris. A Paris escolástica e medieval é tomada pelas novas ideias humanistas que permearam a Teologia e a Filosofia. A gramática, a retórica e as línguas antigas, bem como as artes em geral, ganharam importância e consistência própria. No entanto, foi nos colégios de letras humanas, ou nas faculdades de artes, que se compuseram do trivium - gramática, retórica e lógica - e do quadrivium - aritmética, geometria, música e astronomia -, que o 
humanismo renascentista se consolidou. É este modelo que, tanto jesuítas, quanto protestantes tomaram para seus colégios de alunos externos e que vêm a ser o precursor dos colégios secundários modernos (Garcia-Villoslada, 1991; Miranda, 2001; O’Malley, 2004).

Os colégios seguiram dependendo da Faculdade de Artes, mas num nível inferior. Acima de todas as disciplinas seguiu reinando a Teologia. A lógica, a retórica e a gramática medieval, que pareciam dominar todas as esferas da universidade, cederam espaço para a retórica de Quintiliano (35-100 d.C.), que se converteu na arte e na ciência por excelência e o ponto mais alto dos estudos literários. Para Erasmo, e para todos os humanistas, o estudo da Gramática, do Latim e do Grego estava orientado para obter a eloquência. Esta não era simplesmente uma técnica, mas um estilo de vida. $\mathrm{O}$ vir bônus dicendi peritus - tornar-se um especialista da fala -, como definia Cícero para o orador, oferecia o modelo ideal de humanismo para o homem do Renascimento. O ideal não era somente falar, escrever e comunicar as próprias ideias com propriedade, facilidade e elegância, mas raciocinar, sentir, expressar-se e atuar harmonizando virtude com letras. Virtude e letras era o objetivo em que coincidiam todos os programas dos colégios de Paris. Cícero, César, Virgílio, Horácio, Terêncio, Ovídio, Tácito, Salústio, Homero, Sófocles, Demóstenes, sobretudo, substituíram os manuais medievais (Chervel: Compère, 1997, 1999; Miranda, 2001).

Segundo Pulleda (2001), é necessário ter presente, que o humanismo do Renascimento não era um simples percurso de estudos que transmitiam um conjunto de noções ou fórmulas. Pelo contrário, ele se constituía como um meio para "la educación de la personalidad, para el desarrollo de la libertad y la creatividad humanas, y de todas esas cualidades que sirven para vivir felizmente y con honor en la sociedad de los hombres" (Pulleda, 2001, p.10).

O que denominamos humanismo renascentista, portanto, não significou, em linhas gerais, no pensamento e sensibilidade de seus promotores, uma ruptura com o cristianismo, muito embora tenham ocorrido embates entre ambos. Significou uma mudança na compreensão de imagem do mundo. O ser humano tornou-se o centro de todas as coisas e partícipe ativo da criação divina, por isso, a criatividade e a as artes foram grandemente valorizadas (Chastel, 1963; Colombo, 1990).

Ao desenvolverem os laços entre religião e cultura, letras divinas e letras humanas, o saber sagrado e o profano, os humanistas do século 16 distinguiram-se pela busca de elaboração de uma síntese entre a herança clássica e o cristianismo, na construção de seu saber. Ao fazerem isto preservaram um patrimônio de muitos séculos, que configurou indelevelmente a nossa identidade.

\section{O Modus parisiensis nos colégios e universidades da Companhia de Jesus}

A expressão Modus parisiensis apareceu como um referente pedagógico necessário quando se refere aos colégios e universidades jesuítas ${ }^{3}$ na segunda metade do século 16. É importante esclarecermos que os limites entre o conceito de colégio e o de universidade no início da Companhia de Jesus não eram demarcados como nos tempos atuais. Aldama (1981, p. 146) esclarece que o conceito de colégio e o de universidade "não estavam

\footnotetext{
${ }^{3}$ A área educacional na Companhia de Jesus desde as suas origens foi composta por dois segmentos, os colégios e as universidades. 
claramente demarcados com os primeiros jesuítas como posteriormente na história da Companhia, quando por colégio se entendia simplesmente um centro de estudos humanísticos, e por universidade, um centro de estudos superiores." A universidade abarcava também os estudos humanísticos e nos colégios se podia ensinar não somente letras de humanidades, mas também os estudos acima desta etapa.

\section{Os primeiros planos de estudos baseados no Modus parisiensis}

O Ratio atque Institutio Studiorum Societatis Jesu ${ }^{4}$, como o conhecemos hoje, tratase de um plano de estudos da Companhia de Jesus promulgado oficialmente em 1599 por Claudio Aquaviva, quinto Geral da Companhia de Jesus. Diz Miranda que

não se trata de um escrito teórico sobre educação, mas sim de uma exposição dos métodos e práticas utilizados nos colégios da Companhia durante quase quatro séculos, canonizados após longos anos de experimentação e reflexão nas diferentes províncias religiosas. Trata-se, portanto, da resposta metodológica que a Companhia dava ao seu próprio ideal educativo. (2001, p. 100)

O documento é um conjunto de regras destinadas à organização da vida de estudos nos colégios, tendo como objetivo dar parâmetros para a educação, avaliar as responsabilidades e atribuições e reger as formas de avaliação estabelecendo metas, objetivos e procedimentos universais (Toledo, 2000).

O Ratio foi o resultado de longos anos de elaboração, sendo que desde a concepção das primeiras ideias e dos primeiros documentos que começaram a ser redigidos a pedido do fundador, ou por iniciativa dos jesuítas que trabalhavam nos colégios e universidades, transcorreram cerca de cinquenta anos (Ocampo; Gil, 1992).

Em 1548, com a fundação do Colégio de Messina, o próprio fundador da Ordem solicitou aos padres Hannibal du Coudret, Hieronymus Nadal e Juan de Polanco que elaborassem, de acordo com o Modus parisienses, um plano de estudos. O projeto denominou-se Scopus et ordo scholarum messanensis Societatis lesu e se "constituiu em uma das primeiras referências pedagógicas dos futuros Colégios da Companhia" (Ciordia, 2007. p. 187). Neste mesmo ano, Hieronymus Nadal SI escreveu a Constitutionis Collegii Mesanensis (Companhia de Jesus, Mon Paed, 1965, p.17-28).

Em 1551, Hanníbal du Coudret, escreve o Plano de Estudos de Messina, De Ratione studiorum Collegii Mesanensis (Companhia de Jesus, Mon Paed, 1965, p. 93-106). Neste mesmo ano (1551), foi fundado o Colégio Romano, sendo que o padre Diogo Ledesma escreveu De ratione et ordine Studiorum Collegi Romani, um projeto inacabado (Companhia de Jesus, Mon Paed, 1974, p. 519-627). Em 1552, Hieronymus Nadal escreveu De Studii generalis Dispositione et Ordine (Companhia de Jesus, Mon Paed, 1965 p. 133-163).

\footnotetext{
${ }^{4}$ Convém observar que durante todo o século 17 os jesuítas atribuíam o Ratio no gênero masculino, quando não se referiam à ordem dos estudos. Modernamente outros autores, como Astrain, Rodrigues, Fouqueray e Castellani, continuaram a utilizar o masculino. Contudo, nos dias atuais, utiliza-se o gênero feminino. Neste texto é utilizado o termo masculino, como os jesuítas utilizavam no século 17. 


\section{O estudo de humanidades segundo as Constituições da Companhia de Jesus}

Nesta mesma época (1546-1552), Inácio de Loyola redigia as Constituições, que entrariam em vigor em 1552 (Jaer, 1998). As Constituições são a carta magna da Companhia de Jesus e se constituem num conjunto de princípios normativos, regulativos e orientadores, tanto no sentido apostólico, quanto espiritual, que regem toda a ação da Ordem. Na quarta parte, que trata dos estudos nos colégios e universidades, se manifesta a história do compromisso progressivo da Companhia nascente com a cultura e com as responsabilidades educativas. O título já anuncia: "Como instruir nas letras e em outros meios de ajudar o próximo e os que permanecem na Companhia" (Companhia de Jesus, Constituições, 2004, p.115). Aparecem as linhas mestras pedagógicas e didáticas e, sobretudo, o espírito da atividade pedagógica da Ordem que será desenvolvido no Ratio studiorum de 1599:

Se tivermos em conta que o texto das Constituições data de 1558, podemos observar como, em cerca de quatro décadas, com todas as suas mudanças históricas, culturais e sociais, a Companhia de Jesus pode intuir o alcance pedagógico do ensino escolar formal para a formação de homens virtuosos e sábios (probos simul ac doctos), antecipando assim o princípio que a Ratio exprimiria pelo binômio virtus et litterae. (Miranda, 2011, p. 476)

No proêmio afirma-se o objetivo principal da Companhia: "Ajudar as almas a atingir o fim último para o qual foram criadas [...] para ajudar a melhor conhecer e servir a Deus [...] para isso a Companhia funda colégios e também algumas universidades" (Companhia de Jesus, Constituições, $2004[307]^{5}$, p. 115).

Considerando o fato de que as aulas não eram exclusivamente para a formação dos jesuítas, salienta:

Instituam-se aulas públicas ao menos de estudos humanísticos, e mesmo de estudos superiores, conforme as possibilidades que houver nas regiões onde se encontram tais colégios. [...] nas aulas siga-se um método tal que os que vêm de fora sejam bem instruídos na doutrina cristã. [...] os que estudam humanidades deverão exercitar-se na fala habitual do latim e a fazer composições literárias. (Companhia de Jesus, Constituições, 2004 [392; 395; 447; 464; 466; 468; 470] p.131-144)

$\mathrm{Na}$ quarta parte das Constituições encontra-se, portanto, o núcleo pedagógico que sustenta e regulamenta a ação educativa na Companhia.

\section{As diferentes versões do Ratio}

Em 1552, mesmo ano em que entrou em vigor as Constituições, Hieronymus Nadal SI, escreveu um Ratio denominado De Studii Generalis Dispositione et Ordine e, em 1553, um outro Ratio intitulado Regulae de Scholis Collegiorum (Companhia de Jesus, Mon. Paed. 1965, p. 133-163 e 185-210). Neste mesmo ano o padre Martinus de Olave SI escreveu o Ratio Chamado Ordo Lectionum et Exercitationum in Universitatibus (Companhia de Jesus, Mon. Paed, 1965, p.163-185).

\footnotetext{
${ }^{5}$ Os números entre colchetes indicam os parágrafos, conforme convenção da Companhia de Jesus.
} 
Em 1565 e 1573, na segunda e terceira Congregação Geral da Ordem, já se falava em um corpo de regras gerais conhecidas pelo nome de Summa sapientia e, em 1570, já era usado um Ratio studiorum em alguns colégios da França, Alemanha e Áustria, segundo se conclui a partir das notícias enviadas pelo padre Maldonado, visitador dos colégios da França. (Batllori, 1993; Niebla, 2011). Havia, portanto, iniciativas individuais na produção de documentos, mas não algo em comum e de caráter permanente para toda a Ordem. Todos os documentos produzidos eram transitórios e aplicados em algumas obras educacionais específicas.

De acordo com Klein (1997), a elaboração do Ratio pode ser dividida em dois blocos. O primeiro consistiu na fase de levantamento, verificação e adaptação do material pedagógico produzido pelos colégios da Ordem e ocorreu entre os anos de 1548 e 1583. No segundo, entre 1584 e 1599, foram elaboradas duas versões provisórias do Ratio 1586, não publicada, e 1591. Finalmente a versão definitiva veio a público em 1599.

\section{O Ratio definitivo de 1599}

O que é, no entanto, o Ratio Atque Institutio Studiorum e como podemos identificar o humanismo presente neste documento? O documento que ficou conhecido ao longo da história como Ratio studiorum recolheu, em seus trintas capítulos, o ideal de formação humana que orientou o caráter próprio dos colégios e universidades da Companhia de Jesus. Este aborda uma ampla e completa temática, referente a planos, programas, métodos de estudos, bem como tempos, espaços, ordem e convivência. O conteúdo se apresenta organizado em forma de regras que fazem referência às funções, competências e tarefas das autoridades acadêmicas, seja o provincial, o reitor ou o prefeito de estudos de cada um dos centros docentes. O Ratio de 1599 apresenta o seguinte sumário ${ }^{6}$.

Quadro 1 -

Ratio Atque Institutio Studiorum.

\begin{tabular}{|l|l|}
\hline I - Regras do Provincial & XVIII - Regras do professor da classe superior \\
II - Regras do Reitor & de gramática \\
III - Regras comuns a todos os professores & XIX - Regras do professor da classe média de \\
das faculdades superiores & gramática \\
IV - Regras do professor de Sagrada Escritura & XX - Regras do professor da classe inferior de \\
V- Regras do professor de língua hebraica & gramática \\
VI - Regras do professor de teologia & XXI - Regras dos escolásticos da nossa \\
VII - Regras do professor de casos de & Companhia \\
consciência & XXII - Programa para os que repetem \\
VIII - Regras do professor de filosofia & privadamente a teologia em dois anos \\
IX - Regras do professor de filosofia & XXIII- Regras do ajudante do professor ou \\
X - Regras do professor de filosofia moral & bedel \\
XI - Regras do professor de matemática & XXIV - Regras dos alunos externos da \\
XI I- Regras do prefeito de estudos inferiores & Companhia \\
\hline
\end{tabular}

6 Tradução do sumário em espanhol do Ratio atque Institutio Studiorum Societatis Jesu. Auctoritate Septimae Congregationis Generalis aucta. Antverpiae apud Joan Meursium, 1635. Estão citados apenas os tópicos principais do corpus do Ratio, que apresentam, de certa forma, uma ideia do seu conteúdo. 
XIII - Normas da prova escrita

XIV - Normas para a distribuição de prêmios

$X V$ - Regras comuns aos professores das

classes inferiores

$X V I$ - Regras do professor de retórica

XVII - Regras do professor de humanidades
$X X V I$ - Regras do prefeito da academia

XXVII - Regras da academia dos teólogos e filósofos

XXVIII - Regras do prefeito da academia dos teólogos e filósofos

XXIX - Regras da academia dos retóricos e humanistas

XXX - Regras da academia dos gramáticos

Gonzalbo (1990) identifica nestas regras quatro partes: a primeira delas é relativa ao governo dos colégios e se destina ao provincial e ao reitor responsáveis pela direção dos mesmos. Também estão nelas indicadas as funções do prefeito de estudos, que tem a responsabilidade de tratar diretamente com os alunos, assistir aos exames e controlar a atividade dos mestres. A segunda parte é composta de regras para os professores em geral, e a terceira aborda os estudos elementares com a indicação sobre a distribuição de prêmios. A quarta e última parte contém normas para os estudos superiores, obrigações contraídas pelos estudantes da Companhia em relação aos estudantes externos e à formação e direção das academias como atividades complementar dos estudos, nas quais poderiam se ampliar e aprofundar temas que haviam sido tratados nos cursos.

\section{O Humanismo no Ratio studiorum de 1599}

A partir deste sumário, percebe-se que no Ratio há uma disposição detalhada de regras, que têm como objetivo regulamentar todas as instâncias e atividades das instituições educativas da Companhia de Jesus. No entanto, para compreender o espírito educativo presente no Ratio, é necessário considerar que a religião era a base fundamental de todas as atividades desenvolvidas pelos jesuítas:

A chamada educação jesuítica, não pode jamais ser descolada de uma concepção religiosa, ou seja, os fins, o intuito, o objetivo final dos colégios e do Ratio Studiorum é fornecer uma formação verdadeiramente religiosa. Para isso, se utiliza de uma lógica educativa, que é distribuída pelos níveis, pelos cursos, pela didática, pelos valores, enfim, pelo rigor, como meio, como instrumento para se formarem homens competentes e padres responsáveis e corajosos para assumirem os mais diferentes serviços, especialmente os concernentes às missões. (Costa, 2004, p.224)

As regras do Ratio, portanto, não correspondem exatamente ao sentido que hoje nós damos às normas provenientes de um regulamento. Estas possuem conteúdo espiritual e de visão de mundo. Este princípio está exposto no início da mesma:

Siendo uno de los misterios primarios de nuestra Compañía enseñar a los demás todas las materias que sean conformes con nuestro instituto, con el fin de que se muevan al conocimiento y al amor de nuestro Creador y Redentor: piense con todo cuidado el Propósito Provincial en atender a tan múltiple trabajo de nuestras escuelas, exigido por la gracia de nuestra vocación, para que el fruto responda con abundancia. [Ratio Studiorum, Regra 1 Do Provincial]. (Companhia de Jesus, 1599) 
Mas, em que consistia o programa formativo humanístico do Ratio? Como estava articulado? Abordaremos os aspectos mais característicos da pedagogia jesuíta, assinalando, de maneira especial o humanismo marcadamente cristão aí presente:

A clara organização e abrangência da Summa tornavam-na relativamente fácil de seguir e ensinar. A compreensão de Tomás da relação da filosofia de Aristóteles com a doutrina cristã era consoante ao ensino do Concilio de Latrão. Sua adaptação cristã do ensinamento de Aristóteles de que a virtude se situava a meio caminho entre dois extremos forneceu a fundamentação intelectual básica para o ensino de Inácio. (O'malley, 2004, p. 388)

Ao analisar-se o programa formativo do Ratio, observa-se, que este estava organizado no que podemos denominar uma lógica linear propedêutica, ou seja, um curso prepara imediatamente para o seguinte. Esta organização era semelhante a da Universidade de Paris, onde os jesuítas haviam estudado e se organizava em classes inferiores e faculdades superiores. A formação começava com as Classes Inferiores ou de Letras Humanas, que constavam de aulas de Gramática, Humanidades e Retórica. Terminado este estágio, também denominado Curso de Humanidades, o aluno estava preparado para as Faculdades Superiores, ou seja, a Filosofia e depois a Teologia. O Latim era a língua oficial, que se aprendia nas classes inferiores e era aperfeiçoado na Filosofia e na Teologia (Ocampo, 1999; Romano, 2006).

As Classes Inferiores duravam entre seis a oito anos e o objetivo desta fase de estudos era formar os jovens dentro do espírito cristão. Nesta fase formava-se o humanista, o homem erudito, preparado para ascender aos cursos de Filosofia e Teologia. Estes se preparavam pelo estudo dos clássicos da cultura grego-romana, aprendendo a erudição, a eloquência e o conhecimento de línguas. Nesta etapa a formação humanística consistia no que hoje denominamos formação integral e num estilo de vida na linha do que hoje denominamos excelência humana. Esta se iniciava com a Gramática com três níveis: Ínfima, Média e Superior. Na Gramática Ínfima o estudante aprendia as regras gerais de sintaxe e os princípios da língua grega; nas preleções, elucidavam-se as cartas mais simples de Cícero, as composições escolhidas de Ovídio e outros autores gregos que fossem facilmente compreendidos. O objetivo da Classe Média de Gramática era dar um conhecimento amplo da mesma. Já na Classe Superior exigiase o conhecimento completo da Gramática, sendo que já se utilizavam obras mais densas de Cícero, de Esopo e S. João Crisóstomo (Romano, 2006):

O objetivo desta classe é o conhecimento perfeito dos elementos da gramática, e inicial da sintaxe. Começa com as declinações e vai até a construção comum dos verbos. [...] Nas preleções adotem-se, dentre as cartas de Cícero, só as mais fáceis, escolhidas para este fim, e, se possível, impressas separadamente. [Ratio, regra 1 do professor da classe inferior de gramática]. (Companhia de Jesus, 1599)

Após três ou quatro anos de estudos de Gramática passava-se ao curso de Humanidades com o objetivo de obter "o conhecimento da língua, alguma erudição e uma introdução breve aos preceitos da Retórica" [Ratio studiorum, regra 1, do professor de humanidades]. Os formadores jesuítas acreditavam que as humanidades formavam 0 espírito, auxiliando na formação do homem intelectual, culto e ativo. Pretendia-se formar o 
bom gosto, estimular a aquisição de conhecimentos eruditos que enriquecessem o discurso com expressões elegantes. Estudavam-se historiadores como Cícero, César, Salústio, Tito Lívio, poetas como, Virgílio e Horácio. Aprofundavam-se os estudos em Sócrates, São João Crisóstomo, São Basílio e nas cartas, como as de Platão e Sinésio.

As línguas e literaturas clássicas eram centrais no programa formativo dos colégios e universidades da Companhia. Depois da doutrina cristã, ambas possuíam um caráter especial. Muito embora as línguas vernáculas não tenham uma consideração especial no Ratio de 1599, o simples fato de exigir uma cuidadosa tradução do Latim e do Grego obrigava os estudantes a conhecer melhor sua própria língua (Niebla, 2011).

A Retórica se estudava depois das Humanidades e era de fundamental importância. O principal objetivo era alcançar a eloquência perfeita, que não consistia unicamente na facilidade para falar, escrever e comunicar as próprias ideias com facilidade e elegância, mas na capacidade de raciocinar e expressar-se harmonizando virtude com as letras. Estudavam-se as obras retóricas de Cícero, a retórica de Aristóteles e, eventualmente, a sua Política. Quanto à erudição tirava-se da História, dos costumes das nações, dos autores mais autorizados e de toda a ciência (Miranda, 2001). A respeito deste tema o Ratio assim se expressa:

El grado de esta clase no se puede definir fácilmente con ciertos términos: porque dispone a la perfecta elocuencia, que comprende dos facultades principales, la oratoria y la poesía (y de estas dos se tenga siempre como primera parte a la oratoria) y no solamente sirve para utilidad sino que ayuda al ornato.[...] consta de tres partes principales: los preceptos del hablar, el estilo y la erudición [...] Los preceptos se pueden buscar en todas partes y guardar; pero no han de explicarse sino en la pre lección diaria, a no ser los libros de la retórica de Cicerón, y de Aristóteles tanto la retórica si pareciere como la poética.[...] Ha de añadirse finalmente la erudición de la historia y de las costumbres de los pueblos, de la autoridad de los escritores y de cualquier enseñanza (Ratio Studiorum, regra 1 do professor de retórica). (Companhia de Jesus, 1599)

As Classes Superiores compreendiam o curso de Filosofia com a duração de três anos e o curso de Teologia com quatro anos. Na Filosofia, Aristóteles era o autor obrigatório e, na Teologia, Santo Tomás de Aquino. Além de Santo Tomás faziam parte do currículo da Teologia os estudos de Sagrada Escritura, Regra1-20, e Língua Hebraica, Regra1-5. Em relação a Aristóteles e Santo Tomás, o Ratio se pronuncia da seguinte forma:

en las cosas de alguna importancia no se aparte de Aristóteles, a no ser que contradiga a la doctrina que las academias aprueban en todas partes [...] (Ratio Studiorum, regra 2 do professor de filosofia). A los oyentes de teología y filosofía no les permita cualesquiera libros [...]; es decir, además de la Suma de Santo Tomás para los teólogos y de Aristóteles para los filósofos, algún comentario escogido, que puedan consultar en el estudio particular (Ratio studiorum, regra 30 do prefeito de estudos). (Companhia de Jesus, 1599) 
A Teologia era o ápice da formação, sendo que todos os estudos anteriores preparavam para a mesma. Esta seguia o pensamento escolástico e todos deveriam estudar a Summa theológica de Santo Tomás de Aquino. No entanto, o Ratio precisava certa liberdade de expressão, como podemos ver nas regras seguintes:

Pero no piensen que deben estar tan atados a Santo Tomás que no puedan en cosa alguna apartarse de él; ya que los mismos que se confiesan principalmente tomistas, algunas veces se le apartan, y no está bien que los nuestros se aten a Santo Tomás más que los mismos tomistas (Ratio Studiorum, regra 2 do professor de teologia escolástica). Si alguna vez fuere ambigua la opinión de Santo Tomás o en aquellas cuestiones que tal vez no tocó Santo Tomás y los doctores católicos no convengan entre sí: estará permitido seguir cualquier partido. (Ratio Studiorum, regra 4 do professor de teologia escolástica) (Companhia De Jesus, 1599)

Para compreender as razões da importância da Teologia é necessário considerar que os primeiros jesuítas a concebiam como meio de conduzir o estudante ao conhecimento, ao amor de Deus e a salvação da sua alma. Não havia outro meio mais indicado para isso, portanto, que criar sólidas faculdades de Teologia nas suas universidades. As Letras Humanas, a Filosofia e as Ciências tinham uma função propedêutica em vista de Ciência Teológica. No entanto, esse primado da Teologia não era exclusivo dos jesuítas. É importante lembrar o papel preponderante da Sagrada Escritura no ensino dos protestantes e como Erasmo considerava a leitura dos autores antigos como uma preparação para a leitura da Escritura (Romano, 2006).

O Ratio Studiorum, portanto, é um documento que orientou e dinamizou um programa e um sistema escolar de alcance mundial. O cânone de estudos desenvolvido pelos jesuítas foi mais do que um regulamento, foi um projeto pedagógico elaborado durante cinco décadas. Foi com base neste plano de educação que os jesuítas desenvolveram a sua atividade pedagógica e intelectual ao longo de dois séculos, até 1773, ano da supressão da Companhia, influenciando o pensamento moderno. Muito embora no período em que se estruturou o sistema educativo da Companhia de Jesus havia outros planos de estudos, o Ratio impôs-se pelo fato não destinar-se somente a formação de futuros clérigos, mas também de leigos.

\section{Considerações finais}

Ao introduzir o Modus parisiensis nos seus primeiros colégios e universidades os jesuítas implantaram o que eles mesmos haviam experimentado nos seus anos de estudos. Ao elaborarem o Ratio não criaram nada de original, mas utilizaram as pedras do antigo mundo clássico, para construir uma estrutura educacional própria do seu tempo, caracterizada pelo humanismo renascentista.

Parafraseando o padre Franca (1952), podemos dizer que o método pedagógico desenvolvido pelos jesuítas fundamentou-se e foi estruturado concebendo elementos da sabedoria antiga, utilizando o Cristianismo como a fonte das suas verdades, a Idade Média com a riqueza das experiências filosóficas e o Renascimento com as categorias do Humanismo nascente. Deste modo, durante mais de duzentos anos as Letras e as Humanidades Clássicas tiveram nos jesuítas os seus principais representantes. Os 
autores do Ratio estavam certos de que a formação intelectual com a formação da virtude colaborava para a criação do ideal do homem completo, que bem poderíamos chamar de Paideia humanística cristã.

Para os jesuítas os autores pagãos tinham por isso algo a dizer, pois no seu entender o Humanismo Clássico podia colaborar na elaboração do novo ideal do homem cristão. A dimensão que os primeiros jesuítas deram ao seu ideal pedagógico originou-se da concepção e da convicção de que a formação humana estruturada a partir dos valores espirituais cristãos e do conhecimento intelectual dos Clássicos podia contribuir para a estruturação de uma sociedade melhor. Se as orientações dos seus projetos de estudos são plenamente humanísticas, isso não se deve tão simplesmente a uma adaptação ao gosto da época, nem a uma mera estratégia de combate as heresias, ou mesmo a uma estratégia para melhorar os estudos teológicos. Trata-se de uma concepção de educação intrinsecamente orientada pelos valores do Humanismo Clássico e cristão.

Ao longo da pesquisa ficou claro que não foi fácil definir operativamente esta empresa, pois nela intervieram complexos e variados fatores, cuja explicação poderia começar com a resposta a esta pergunta: os jesuítas, do ponto de vista da missão e da pedagogia, tinham algo de novo a oferecer a inquietante e dinâmica sociedade cultural do século 16? A partir de nosso trabalho de pesquisa, podemos afirmar que sim, pois a proposta educacional desenvolvida pela Companhia de Jesus contribuiu significativamente, tanto para a educação e a docência, quanto para as reformas morais, religiosas e para afirmar a condição humana e cristã do homem enquanto protagonista da história.

A partir dos séculos 15 e 16 o impulso da técnica, a invenção da imprensa, as descobertas e viagens marítimas impulsionaram a Europa para uma recriação conceptual e uma transformação que abarcou os mais diversos âmbitos da sociedade, tanto cultural, quanto político, econômico, social e religioso. Os jesuítas fizeram parte de todo esse dinamismo, enquanto fundadores e mestres de colégios, pregadores, missionários, humanistas, pedagogos, poetas, matemáticos, cientistas, físicos, astrônomos, arquitetos e enquanto promotores desse encontro de culturas que acompanhou o nascimento do mundo moderno.

\section{Referências}

ALDAMA, Antonio M. Iniciación al estudio de las constituciones. Roma: Centrum Ignatianum spiritualitatis, 1981.

AQUINO, Marcelo F. Teologia latino-americana e humanismo social cristão. In: OSOWSKI, Cecília (org.). Teologia e humanismo social cristão: traçando rotas. São Leopoldo: Unisinos, 2000. p. 67-90.

BATLLORI, Miguel. San Ignacio y la fundación de los jesuitas. In: DELGADO, Criado Buenaventura. Historia de la educación en España y América. Madrid: Morata-SM, 1993, v. 2, p. 57-64.

CHASTEL, André; KLEIN, Robert. L'Europe de la renaissance, l'age de l'humanism. Bruxelles: Éditions de la Connaissance, 1963.

CHERVEL, André. COMPĖRE, Marie- Madeleine. As humanidades no ensino. Educação e Pesquisa, São Paulo, v. 25, n. 2, 1999, p. 149-170. 
CIORDIA, Javier Vergara. El humanismo pedagógico en los colegios jesuíticos del siglo XVI. Studia Philologica Valentina, Valência, Uned, v. 10, n. 7, 2007, p.171-200.

CODINA MIR, Gabriel. Aux sources de la pédagogie des jésuites: le modus parisiensis. Roma: Tipografia Editrice M. Pisani, 1968.

COLOMBO, Célia. Humanismo y renacimiento. Madrid: Cincel-Kapelusz, 1990.

COMPANHIA DE JESUS. Constituições e normas complementares. São Paulo: Loyola, 2004.

COMPANHIA DE JESUS. Diogo de Ledesma SI. De ratione et ordine studiorum Collegii Romani 1564-1565. In: Monumenta Paedagogica Societatis lesu. Edidit: Ladislaus Lukács S.I. Romae: Institutum Historicum Societatis lesu, 1974, v. 107, (1557-1572), p. 519-627.

COMPANHIA DE JESUS. Hanníbal du Coudret. De Ratione studiorum Collegii Mesanensis. In: Monumenta paedagogica Societatis lesu. Edidit: Ladislaus Lukács S.I Romae: Institutum Historicum Societatis lesus, 1965, v. 92, (1540-1556), p. 93-106.

COMPANHIA DE JESUS. Hieronymus Nadal SI. Constitutiones Collegii Messanensis/ Studii Generalis Dispositione et Ordine/Regulae de Scholis Collegiorum.In: Monumenta Paedagogica Societatis lesu. Edidit: Ladislaus Lukács S.I Romae: Institutum Historicum Societatis lesus, 1965, v. 92, (1540-1556), p. 17-28/133-163/185-210.

COMPANHIA DE JESUS. Martinus de Olave SI. Ordo Lectionum et Exercitationum in Universitatibus. In: Monumenta Paedagogica Societatis lesu. Edidit: Ladislaus Lukács S.I Romae: Institutum Historicum Societatis lesus, 1965, v. 92, (1540-1556), p.163-185.

COMPANHIA DE JESUS. Ratio atque institutio studiorum societatis iesus. Auctoritate Septimae. (Reedição publicada em Roma em 1616).

COSTA, Célio Juvenal. A racionalidade jesuítica em tempos de arredondamento do mundo: o Império Português (1540-1599). Piracicaba: Unimep, 2004. 304f. Tese (doutorado em Educação). Programa de Pós-Graduação em Educação.

FERNAND, Robert. L'humanisme, essai de définition. Paris: Belles-Lettres, 1946.

FRANCA, Leonel. O método pedagógico dos jesuítas. Rio de Janeiro: Agir 1952.

GARCIA-VILLOSLADA, Ricardo. Santo Inácio de Loyola: nova biografia. São Paulo: Loyola, 1991.

GIL, Eusebio. El sistema educativo de la Compañía de Jesús: la Ratio Studiorum. Madrid: Universidad Pontificia de Comillas, 1992.

GIULIANI, Maurice. Ignace de Loyola, Écrits. Coll. Christus n. 76, Paris: Desclée de Brower, Bellamim, 1991.

GOMES, Joaquim Ferreira. Para a história da educação em Portugal. Porto: Porto, 1995.

GONZALBO, Aizpuru Pilar. Historia de la educación en la época colonial: la educación de los criollos y la vida urbana. México: El Colegio de México, 1990.

IPARRAGUIRE, Ignacio. Obras completas de San Ignacio de Loyola. Madri: BAC, 1963. JAER, André de. Formar un cuerpo para la misión: lectura sapiencial de las constituciones de la Compañía de Jesús. Santander: Sal Terrae, 1998.

JULIA, Dominique. A cultura escolar como objeto histórico. Revista Brasileira de História da Educação, Maringá, n. 1, 2000, p. 9-43.

KLEIN, Luiz Fernando. Atualidade da pedagogia jesuítica. São Paulo: Loyola, 1997. 
KOLVENBACH, Peter-Hans. Discurso de pe. Peter-Hans Kolvenbach aos membros do grupo de trabalho sobre a pedagogia inaciana: uma proposta prática. Villa Cavalleti: Roma, 1993.

LOYOLA, Inácio. Escritos: o relato do peregrino. São Paulo: Loyola, 2006.

MIRANDA, Margarida. Uma paidéia humanística: a importância dos estudos literários na pedagogia jesuítica do século XVI. Humanitas, Coimbra, v.67, 1996, p. 223-256.

MIRANDA, Margarida. Humanismo jesuítico e identidade da Europa: uma comunidade pedagógica europeia'. Hvmanitas, Coimbra, v. 53, 2001, p. 83-111.

NIEBLA, Gilberto Guevara. Clássicos del pensamiento pedagógico mexicano. México: Secretaria de Educación Pública/INEHRM, 2011.

O’MALLEY, John. Os primeiros jesuítas. São Leopoldo: Unisinos; Bauru: Edusc, 2004.

O’NEILL, Chales E; DOMíNGUES, Joaquín Maria. Dicionário histórico de la Compañía de Jesus biográfico-temático. Madrid: Universidade Pontificia de Comillas, 2001, v. 3. Institutum Historicum, S.I

OCAMPO Flórez Esteban. Claves de la Ratio Studiorum para la letctura de la propuesta educativa de la Comañía de Jesús hoy. SEMINARIO TALLER INTERNACIONAL SOBRE LA RATIO STUDIORUM, Cali, 1999. Anais... Cali: Universidad Javeriana, Colegio San Juan Berchmans, 1999, p. 1-29.

PULLEDA, Salvatore. Un humanista contemporáneo, escritos y conferencias de Salvatore Pulleda. Santiago de Chile: Virtual, 2001.

ROMANO, Antonela. II Messanense Collegium Prototypum Societatis lesu. Bolonha, Clueb, 2002.

SOARES, Nair de Nazaré C. Humanismo e pedagogia. Hvmanitas, Coimbra, v. 67, 1985, p. 799-844.

TOLEDO, Cezar Alencar A. Razão de estudos e razão política: um estudo sobre a Ratio Studiorum. Universidade Estadual de Maringá, Acta Scientiarum, v. 22, n. 1, 2000, p.181187.

TOLEDO, Cezar Alencar A; RUCKSTADTER, Flávio Massami M. A filosofia educacional dos jesuítas nas cartas do pe. José de Anchieta. Acta Scientiarum, Maringá, v. 25, n. 2, 2003, p. 257-265.

VAZ, Cláudio Henrique de Lima. Humanismo hoje: tradição e missão. Síntese Revista de Filosofia, Belo Horizonte, v. 28, n. 91, 2001, p. 13-14.

VERGER, Jacques. La faculté des arts: le cadre institutionnel. In: WEIJERS, Olga (ed.). Le maniement du savoir: pratiques intellectuelles à l'époque des premières universités: XIIle-XIVe siècles. Belgium: Turnhout, Brepols Publishers, 1997, p. 17-42.

WEIJERS, Olga. La disputati. Belgium: Turnhout Brepols Publishers, 1997c.

WEIJERS, Olga. L'enseignement des disciplines à la faculté des arts, Paris et Oxford, XIIle-XIVe siècles. ACTES DU COLLOQUE INTERNATIONAL. Belgium: Turnhout, Brepols Publishers, 1997a.

WEIJERS, Olga. Techniques et méthodes d'enseignement. Belgium: Turnhout Brepols Publishers, 1997b. 
JOÃO BATISTA STORCK é estudante do curso de doutorado em Educação na Universidade do Vale do Rio dos Sinos.

Endereço: Rua Padre Aloysio Sehnen, 186 - São Leopoldo - RS - Brasil. E-mail: jbssj@hotmail.com.

Recebido em 5 de agosto de 2015.

Aceito em 30 de setembro de 2015. 